\title{
Delayed (“Secondary") Cerebral Energy Failure after Acute Hypoxia-Ischemia in the Newborn Piglet: Continuous 48-Hour Studies by Phosphorus Magnetic Resonance Spectroscopy
}

\author{
ANN LOREK, Y. TAKEI, E. B. CADY, J. S. WYATT, JULIET PENRICE, A. D. EDWARDS, \\ D. PEEBLES, MARZENA WYLEZINSKA, H. OWEN-REECE, V. KIRKBRIDE, C. E. COOPER, \\ R. F. ALDRIDGE, S. C. ROTH, G. BROWN, D. T. DELPY, AND E. O. R. REYNOLDS \\ Departments of Paediatrics [A.L., Y.T., J.S.W., J.P., A.D.E., D.P., H.O.-R. V.K., C.E.C., S.C.R., \\ E.O.R.], Medical Physics and Bioengineering [E.B.C., M.W., R.F.A., D.T.D.], and Biochemistry \\ and Molecular Biology [G.B.], University College London, London, United Kingdom
}

\section{AHSTRACT}

Phosphorus $\left({ }^{31} \mathrm{P}\right)$ spectra from the brains of severely birth-asphyxiated human infants are commonly normal on the first day of life. Later, cerebral energy failure develops, which carries a serious prognosis. The main purpose of this study was to test the hypothesis that this delayed ("secondary") energy failure could be reproduced in the newborn piglet after a severe acute reversed cerebral hypoxicischemic insult. Twelve piglets were subjected to temporary occlusion of the common carotid arteries and hypoxemia [mean arterial $\mathrm{PO}_{2} 3.1(\mathrm{SD} 0.6) \mathrm{kPa}$ ]. Mean cerebral phosphocreatine concentration [PCr]/inorganic orthophosphate concentration [Pi] decreased from 1.40 (SD 0.29) to 0.01 (SD 0.02 ), and nucleotide triphosphate concentration [NTP]/ exchangeable phosphate pool concentration [EPP] decreased from 0.19 (SD 0.02) to 0.06 (SD 0.04) $(p<0.001$ for each decrease). On reperfusion and reoxygenation of the brain, mean $[\mathrm{PCr}] /[\mathrm{Pi}]$ and $[\mathrm{NTP}] /[\mathrm{EPP}]$ returned to baseline. Observations continuing for the next $48 \mathrm{~h}$ showed that $[\mathrm{PCr}] /[\mathrm{Pi}]$ again decreased, in spite of normal arterial $\mathrm{Po}_{2}$, mean arterial blood pressure, and blood glucose, to 0.62 (SD $0.61)$ at $24 \mathrm{~h}(p<0.01)$ and $0.49(\mathrm{SD} \mathrm{0.37)})$ at $48 \mathrm{~h}(p<$ $0.001)$. [NTP]/[EPP] also decreased, but to a lesser degree. Intracellular $\mathrm{pH}$ remained unchanged. These findings appeared identical with those seen in birth-asphyxiated human infants. No changes in cerebral metabolite concentrations took place in six control piglets. The severity of secondary energy failure, as judged by the lowest $[\mathrm{PCr}] /[\mathrm{Pi}]$ recorded at
$24-48 \mathrm{~h}$, was directly related to the extent of acute energy depletion, obtained as the time integral of reduction in $[\mathrm{NTP}] /[\mathrm{EPP}](p<0.0001)$. This animal model of secondary energy failure may prove useful for testing cerebroprotective strategies. (Pediatr Res 36: 699-706, 1994)

\section{Abbreviations}

[EPP], exchangeable phosphate pool concentration FID, free induction decay

$\mathrm{FiO}_{2}$, inspired oxygen fraction

MABP, mean arterial blood pressure

MRS, magnetic resonance spectroscopy

NTP, nucleotide triphosphate

[NTP], nucleotide triphosphate concentration

${ }^{31} \mathbf{P}$, phosphorus

$\mathrm{PaCO}_{2}$, arterial partial pressure of carbon dioxide

$\mathbf{P a O}_{2}$, arterial partial pressure of oxygen

PCr, phosphocreatine

[PCr], phosphocreatine concentration

PEt, phosphoethanolamine

$\mathbf{p H}_{\mathrm{a}}$, arterial $\mathrm{pH}$

pH $_{\mathrm{i}}$, intracellular $\mathrm{pH}$

$\mathbf{P i}$, inorganic orthophosphate

[Pi], inorganic orthophosphate concentration

PME, phosphomonoester

[Ptot], total detectable phosphorus concentration

$\mathbf{T}_{\mathbf{R}}$, repetition time
${ }^{31} \mathbf{P}$ magnetic resonance spectra from the brains of babies with evidence of critically impaired intrapartum

Received February 8, 1994; accepted July 7, 1994

Correspondence and reprint requests: Dr. Ann Lorek, Department of Paediatrics, University College London Medical School, Rayne Institute, University Street, London WC1E 6JJ, UK.

Supported by Action Research, the Medical Research Council, the Wellcome Trust, and the Wolfson Foundation. gas exchange ("birth asphyxia") were commonly normal on the first day of life $(1,2)$. Subsequently, impairment of cerebral energy metabolism developed in some of the babies, as shown by decreasing $[\mathrm{PCr}] /[\mathrm{Pi}]$ and eventually, in very severely affected ones, by a reduction in [NTP] [which is composed largely of ATP $(3,4)]$. These changes in cerebral energetics took place without a decrease in $\mathrm{pH}_{\mathrm{i}}$ and in the absence of any evidence of 
Table 2. Physiologic variables in the experimental group $(n=12)^{*}$

\begin{tabular}{lccccc}
\hline & \multicolumn{5}{c}{ Time (h) } \\
\cline { 2 - 5 } & Baseline & 0 & 2 & 24 & 48 \\
\hline $\mathrm{PaO}_{2}(\mathrm{kPa})$ & $11.4(3.6)$ & $3.1 \dagger(0.6) \ddagger$ & $11.6(3.5)$ & $13.7(3.4)$ & $13.4(2.7)$ \\
$\mathrm{PaCO}_{2}(\mathrm{kPa})$ & $5.8(1.4)$ & $6.6(1.4) \S$ & $6.3(1.9)$ & $5.7(1.5)$ & $5.3(1.4)$ \\
$\mathrm{BE}_{\mathrm{a}}\left(\mathrm{mmol} \cdot \mathrm{L}^{-1}\right)$ & $3.8(2.9)$ & $-5.7 \dagger(5.1) \ddagger$ & $1.0 \|(2.6)$ & $2.2(2.7)$ & $1.0(3.0)$ \\
$\mathrm{pH}$ & $7.45(0.06)$ & $7.26 \dagger(0.12) \ddagger$ & $7.36(0.10)$ & $7.40(0.03)$ & $7.42(0.08)$ \\
$\mathrm{Blood}$ glucose $\left(\mathrm{mmol} \cdot \mathrm{L}^{-1}\right)$ & $8.3(1.0)$ & $9.8(2.0)$ & $8.4(0.3)$ & $7.6(1.0)$ & $8.1(1.9)$ \\
$\mathrm{MABP}(\mathrm{kPa})$ & $7.72(0.82)$ & $5.41 \dagger(0.78) \ddagger$ & $7.36(1.18)$ & $7.71(1.30)$ & $7.92(1.41)$ \\
$\mathrm{Heart} \mathrm{rate}\left(\min ^{-1}\right)$ & $172(20)$ & $223 \|(23) \ddagger$ & $205(34)$ & $185(26)$ & $174(26)$ \\
Rectal temperature $\left({ }^{\circ} \mathrm{C}\right)$ & $38.5(0.5)$ & $38.4(0.4)$ & $38.7(0.4)$ & $38.6(0.5)$ & $38.6(0.4)$ \\
\hline
\end{tabular}

* Times are from the start of resuscitation (at $0 \mathrm{~h}$ ) after the acute insult. Values are mean (SD). $\mathrm{BE}_{\mathrm{a}}$, arterial base excess. At time $0, n=11$ for $\mathrm{PaO}_{2}, \mathrm{PaCO}_{2}, \mathrm{BE}_{\mathrm{a}}, \mathrm{pH}_{\mathrm{a}}$, and blood glucose because of temporary catheter block in one animal. At $24 \mathrm{~h} n=12$ and at $48 \mathrm{~h} n=10$ because two animals died at 40 and $42 \mathrm{~h}$. Analysis of variance on both groups of animals (excluding insult time 0$)$ showed that changes in $\operatorname{PaO}_{2}(p<0.05), \mathrm{BE}_{\mathrm{a}}(p<$ $0.01)$, and HR $(p<0.01)$ were all related to time. Heart rate $(p<0.05)$ was also related to hypoxia-ischemia.

$\dagger p<0.001$ for difference from baseline (paired $t$ test).

$\ddagger p<0.001$ for difference from controls at equivalent time (unpaired $t$ test). Baseline and time 0 were compared with baseline time 0 in controls. $\S p<0.01$ for difference from controls at equivalent time (unpaired $t$ test).

$\| p<0.01$ for difference from baseline (paired $t$ test).

ischemic insult; heart rate and $\mathrm{PaCO}_{2}$ increased. These variables subsequently returned to normal.

${ }^{31} P$ MRS. A typical baseline ${ }^{31} \mathrm{P}$ spectrum is illustrated in Figure 1. Eleven peaks could be identified from their characteristic resonance frequencies (15). The peaks were assigned, from left to right, to two PME (PEt and phosphocholine); a bifid peak due to $\mathrm{Pi}$; two phosphodiesters (phosphatidylethanolamine and phosphatidylcholine); PCr; the $\gamma, \alpha$, and $\beta$ peaks of NTP; and, between the $\alpha$ and $\beta$ peaks, NAD plus NADH and uridine diphosphate sugars.

Figure 2 shows the changes in the spectra that took place in an animal subjected to an acute cerebral hypoxicischemic insult lasting $43 \mathrm{~min}$ that caused severe intracellular acidosis and depletion of high-energy metabolites, which was followed by recovery and later by depletion of $[\mathrm{PCr}] /[\mathrm{Pi}]$ and $[\mathrm{NTP}] /[\mathrm{EPP}]$ without intracellular acidosis.

Mean values for metabolite ratios and $\mathrm{pH}_{\mathrm{i}}$ in the control and experimental groups are given in Tables 3 and 4, respectively. No changes took place over $48 \mathrm{~h}$ in the

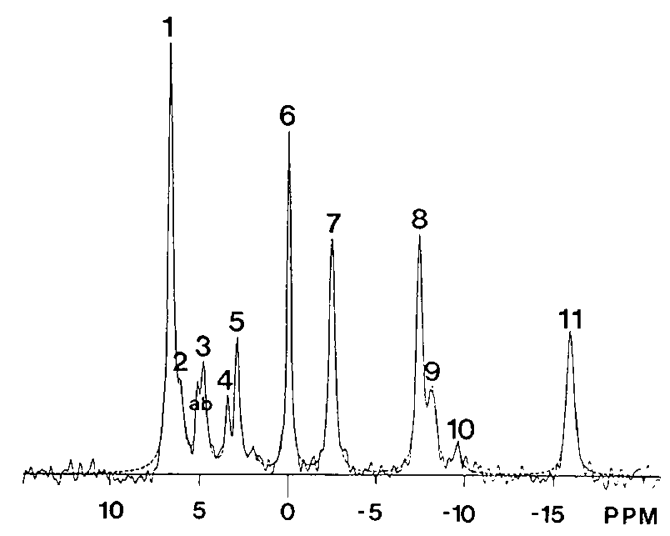

Figure 1. ${ }^{31} \mathrm{P}$ spectrum from a control animal. Resonances are assigned as follows: 1 , PEt; 2, phosphocholine; $3 a$ and $b$, Pi components; 4, phosphatidylethanolamine; 5, phosphatidylcholine; $6, \mathrm{PCr} ; 7, \gamma-\mathrm{NTP}$; $8, \alpha-\mathrm{NTP} ; 9, \mathrm{NAD}$ and NADH; 10 , uridine diphosphate sugars; and 11 , $\beta-N T P$. control group. In the experimental group, $[\mathrm{PCr}] /[\mathrm{Pi}] \mathrm{de}-$ creased during the insult from 1.40 (SD 0.29) to 0.01 (SD 0.02 ); this was due to a reduction in [PCr] together with a reciprocal and then larger increase in [Pi]. The Pi peak broadened and appeared to include several components indicating a range of compartments with different $\mathrm{pH}_{\mathrm{i}}$. Eventually, the Pi peak narrowed at a chemical shift indicating a $\mathrm{pH}_{\mathrm{i}}$ of $5.84(\mathrm{SD} 0.30)$ compared with a baseline value of 7.06 (SD 0.05). Many other resonances (e.g. PEt, phosphocholine, and $\gamma$ - and $\beta$-NTP) also showed acid chemical shifts (data not given), and the broadening of the $\gamma$-NTP peak was also attributable to very low $\mathrm{pH}_{\mathrm{i}}$, as previously found in vitro (14).

When $[\mathrm{PCr}] /[\mathrm{Pi}]$ and $[\mathrm{PCr}] /[\mathrm{Ptot}]$ had started to decrease, $[\mathrm{NTP}] /[\mathrm{EPP}]$ and $[\mathrm{NTP}] /[\mathrm{Ptot}]$ began to decline but at a slower rate; immediately before resuscitation [NTP]/[EPP] had fallen from 0.19 (SD 0.02) to 0.06 (SD 0.04). During hypoxia-ischemia, the PME region of the spectrum became difficult to analyze in terms of individual constituents. PME concentration/[Ptot] increased, possibly in part due to the generation of sugar phosphate resonances in the PME region. Two $h$ after resuscitation began, all the abnormal values had on average reverted to or close to baseline, although $[\mathrm{NTP}] /[\mathrm{EPP}]$ was slightly lower than in controls. Recovery of $[\mathrm{PCr}] /[\mathrm{Pi}]$ and [NTP $] /$ [EPP] was incomplete in two animals, although both indices returned to within $3 \mathrm{SD}$ of mean baseline values within $5 \mathrm{~h}$. Table 4 also shows that by $24 \mathrm{~h}$ after the insult mean $[\mathrm{PCr}] /[\mathrm{Pi}]$ had again fallen below baseline and control values and decreased further to $0.49(0.37)$ by $48 \mathrm{~h}$. [NTP]/[EPP] was also decreasing by $24 \mathrm{~h}$. No change took place in $\mathrm{pH}_{\mathrm{i}}$. Data for $[\mathrm{PCr}] /[\mathrm{Pi}]$ for the control and experimental groups are summarized in Figure 3. Inspection of data from individual piglets showed that progressive deterioration in $[\mathrm{NTP}] /[\mathrm{EPP}]$ took place in eight animals, whereas in three animals recovery was under way by $32-42 \mathrm{~h}$. There was no change in [NTP]/ [EPP] in one animal, although $[\mathrm{PCr}] /[\mathrm{Pi}]$ declined slightly. 

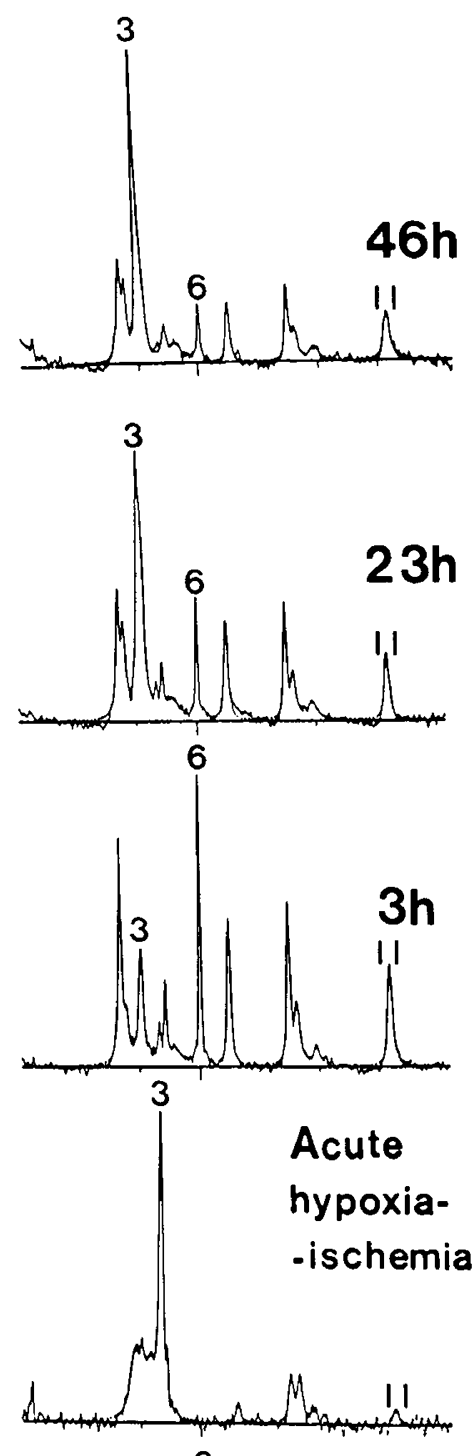

6

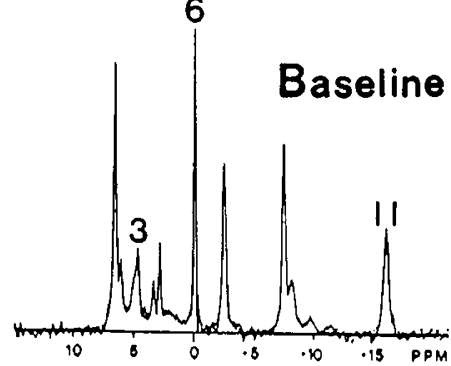

Figure 2. Series of spectra from an animal subjected to 43 min of acute cerebral hypoxia-ischemia. $\mathrm{Pi}$ (peak 3), $\mathrm{PCr}$ (peak 6), and $\beta$-NTP (peak 11) are assigned as in Figure 1. The spectrum during the hypoxicischemic insult was obtained immediately before resuscitation (time 0 ). Subsequent spectra have been timed from the start of resuscitation. During hypoxia-ischemia, $[\mathrm{PCr}] /[\mathrm{Pi}]$ and $[\mathrm{NTP}] /[\mathrm{EPP}]$ decreased from 1.20 to 0.00 and 0.18 to 0.04 , respectively, and $\mathrm{pH}_{\mathrm{i}}$ decreased from 7.10 to 6.34. $[\mathrm{PCr}] /[\mathrm{Pi}]$ and $[\mathrm{NTP}] /[\mathrm{EPP}]$ recovered to 1.17 and 0.18 at $3 \mathrm{~h}$ before decreasing again over the next $2 \mathrm{~d}$ to 0.12 and 0.12 at $46 \mathrm{~h} . \mathrm{pH}_{\mathrm{i}}$ at $3 \mathrm{~h}$ was 7.11 , at $23 \mathrm{~h} 6.94$, and at $46 \mathrm{~h} \mathrm{7.19.}$

Figure 4 shows that a positive linear relationship was found between the severity of the acute cerebral hypoxicischemic insult, as determined by the time integral of depletion of $[\mathrm{NTP}] /[\mathrm{EPP}]$, and the minimum value for
Table 3. Cerebral ${ }^{31} \mathrm{P}$ metabolite ratios and $\mathrm{pH}_{i}$ in the control group $(n=6) *$

\begin{tabular}{lcccc}
\hline & \multicolumn{4}{c}{ Time (h) } \\
\cline { 2 - 5 } & 0 & 2 & 24 & 48 \\
\hline$[\mathrm{PCr}] /[\mathrm{Pi}]$ & $1.45(0.31)$ & $1.27(0.19)$ & $1.50(0.24)$ & $1.49(0.40)$ \\
[PCr]/[Ptot] & $0.13(0.01)$ & $0.12(0.01)$ & $0.14(0.01)$ & $0.15(0.01)$ \\
[Pi]/[Ptot] & $0.09(0.01)$ & $0.10(0.01)$ & $0.10(0.01)$ & $0.10(0.02)$ \\
[NTP]/[EPP] & $0.21(0.01)$ & $0.20(0.00)$ & $0.20(0.01)$ & $0.19(0.01)$ \\
[NTP]/[Ptot] & $0.12(0.01)$ & $0.12(0.00)$ & $0.12(0.01)$ & $0.12(0.01)$ \\
[PME]/[Ptot] & $0.21(0.01)$ & $0.21(0.01)$ & $0.20(0.01)$ & $0.19(0.02)$ \\
[PDE]/[Ptot] & $0.10(0.02)$ & $0.11(0.02)$ & $0.10(0.01)$ & $0.11(0.02)$ \\
[NAD+NADH]/[Ptot] $]$ & $0.08(0.01)$ & $0.07(0.01)$ & $0.07(0.01)$ & $0.06(0.01)$ \\
[UDP]/[Ptot] & $0.02(0.01)$ & $0.02(0.01)$ & $0.03(0.01)$ & $0.02(0.01)$ \\
pH & $7.04(0.03)$ & $7.04(0.02)$ & $7.08(0.03)$ & $7.07(0.02)$ \\
\hline
\end{tabular}

* Times are from the first observations made (at $0 \mathrm{~h}$ ) and 2, 24, and 48 $\mathrm{h}$ afterward. Values are mean (SD). [PDE], phosphodiester concentration; [UDP], uridine diphosphate sugar concentration.

[PCr] $/[\mathrm{Pi}]$ at $24-48 \mathrm{~h}(r=0.91, p<0.0001)$. A similar relation was found between the acute decrement of $[\mathrm{NTP}] /[\mathrm{Ptot}]$ and minimum $[\mathrm{PCr}] /[\mathrm{Pi}]$ at $24-48 \mathrm{~h}(r=$ $0.87, p<0.0003$ ).

Neuropathology. Histologic examination of the brains of the experimental group of animals (Squier MV, Gould S, personal communication) showed damage involving the cerebral and cerebellar cortex, basal ganglia, cerebral white matter, and brain stem in descending order of severity. Two separate patterns of neuronal changes were seen. Neuronal cytoplasmic eosinophilia with dissolution of the nuclear membrane and loss of nuclear staining were found in some of these areas, and in others intense nuclear basophilia with shrinkage or fragmentation of nuclear material into densely staining round granules, suggestive of apoptotic cell death. In the more severely damaged brains, there was edema, microglial reaction, and astrocytic proliferation in the white matter. A full account of the histopathologic findings will be published separately.

\section{DISCUSSION}

The major purpose of this study was to test the hypothesis that the sequence of cerebral metabolic changes that follows severe birth asphyxia in human infants, and that we have described as secondary energy failure $(1,2,5,6)$, could be reproduced in the newborn piglet. This animal was chosen because the brain is comparable to, although in some ways slightly more mature than, the brain of a human infant (16), because it has been well characterized by previous investigators $(9,17)$, and because it is large enough to allow simultaneous studies by MRS and other techniques. The animal is similar in size to a preterm infant, so methods for monitoring physiologic variables and maintaining it in good condition for more than $48 \mathrm{~h}$ were readily available. The anesthetic agents were chosen to provide satisfactory anesthesia without causing effects that would interfere with the interpretation of the results. Isoflurane, which was used as the main anesthetic, reduces cerebral metabolic rate (18), and nitrous oxide, which was also used, are known to increase cere- 
Table 4. Cerebral ${ }^{31} \mathrm{P}$ metabolite ratios and $\mathrm{pH}_{i}$ in the experimental group $(n=12)^{*}$

\begin{tabular}{|c|c|c|c|c|c|}
\hline & \multicolumn{5}{|c|}{ Time $(\mathrm{h})$} \\
\hline & Baseline & 0 & 2 & 24 & 48 \\
\hline$[\mathrm{PCr}] /[\mathrm{Pi}]$ & $1.40(0.29)$ & $0.01 \dagger(0.02)$ & $1.32(0.46)$ & $0.62 \div(0.61) \|$ & $0.49 \dagger(0.37) \S$ \\
\hline$[\mathrm{PCr}] /[\mathrm{Ptot}]$ & $0.13(0.01)$ & $0.00 \dagger(0.01) \S$ & $0.14(0.02)$ & $0.09 \quad(0.05) \|$ & $0.09 \div(0.04) \S$ \\
\hline$[\mathrm{Pi}] /[\mathrm{Ptot}]$ & $0.10(0.02)$ & $0.42 \div(0.08) \S$ & $0.12(0.04)$ & $0.31 \ddagger(0.24) \|$ & $0.25 \dagger(0.10) \S$ \\
\hline$[\mathrm{NTP}] /[\mathrm{EPP}]$ & $0.19(0.02)$ & $0.06 \dagger(0.04) \S$ & $0.18(0.00) \S$ & $0.13 \div(0.07) \|$ & $0.15 \ddagger(0.03) \|$ \\
\hline$[\mathrm{NTP}] /[\mathrm{Ptot}]$ & $0.11(0.01)$ & $0.03 \dagger(0.02) \S$ & $0.10(0.01) \|$ & $0.08 \quad(0.05) \|$ & $0.10 \div(0.02) \|$ \\
\hline [PME]/[Ptot] & $0.21(0.02)$ & $0.32 \dagger(0.06) \S$ & $0.21(0.02)$ & $0.16 \quad(0.05)$ & $0.19 \quad(0.03)$ \\
\hline$[\mathrm{PDE}] /[\mathrm{Ptot}]$ & $0.11(0.02)$ & $0.03 \dagger(0.02) \S$ & $0.11(0.02)$ & $0.10 \quad(0.05)$ & $0.11 \quad(0.06)$ \\
\hline$[\mathrm{NAD}+\mathrm{NADH}] /[\mathrm{Ptot}]$ & $0.07(0.02)$ & $0.07 \quad(0.01)$ & $0.07(0.01)$ & $0.05 \div(0.01) \|$ & $0.05 \div(0.02)$ \\
\hline$[\mathrm{UDP}] /[\mathrm{Ptot}]$ & $0.03(0.01)$ & $0.02 \quad(0.02)$ & $0.02(0.01)$ & $0.02(0.01)$ & $0.02(0.01)$ \\
\hline $\mathrm{pH}_{\mathrm{i}}$ & $7.06(0.05)$ & $5.84 \dagger(0.30) \S$ & $7.02(0.10)$ & $6.89 \quad(0.36)$ & $7.09 \quad(0.08)$ \\
\hline
\end{tabular}

* Times are taken from the start of resuscitation after the acute insult. At $24 \mathrm{~h} n=11$ because of temporary spectrometer failure, and at $48 \mathrm{~h}$ $n=10$ because two animals died with severe brain injury. Values are mean (SD). [PDE], phosphodiester concentration; [UDP] uridine diphosphate sugar concentration. Analysis of variance comparing the experimental and control groups (omitting values at insult time 0 ) showed differences in $[\mathrm{PCr}] /[\mathrm{Pi}](p<0.001),[\mathrm{PCr}] /[\mathrm{Ptot}](p<0.05),[\mathrm{Pi}] /[\mathrm{Ptot}](p<0.001),[\mathrm{NTP}] /[\mathrm{EPP}](p<0.001),[\mathrm{NTP}] /[\mathrm{Ptot}](p<0.01),[\mathrm{PME}] /[\mathrm{Ptot}]($ time dependent $p<0.05)$, and $[\mathrm{NAD}] /[$ Ptot $](p<0.001)$.

$\dagger p<0.001$ for differences from baseline (paired $t$ test).

$\ddagger p<0.01$ for differences from baseline (paired $t$ test).

$\S p<0.001$ for difference from controls at equivalent time (unpaired $t$ test).

$\| p<0.01$ for difference from controls at equivalent time (unpaired $t$ test).

bral blood flow (17). The data given in Table 1 demonstrate that a range of physiologic variables in both the experimental and control groups of animals remained at satisfactory levels throughout the studies.

MRS was carried out using surface coil localization, and because of the high field strength it was possible to obtain spectra of good quality. Corrections for saturation were not required (because of the long $T_{R}$ ), so accurate estimates of the relative concentrations of the ${ }^{31} \mathrm{P}$ metabolites could be obtained irrespective of whether spinlattice relaxation rates altered. The volume of brain interrogated, approximately $4 \mathrm{~mL}$, included the occipitoparietal regions, and the spectra appeared uncontaminated from extracerebral tissue, inasmuch as $[\mathrm{PCr}] /[\mathrm{Pi}]$ decreased to zero in the animals that were worst affected by secondary energy failure, although tissues other than the brain remained well oxygenated and perfused.

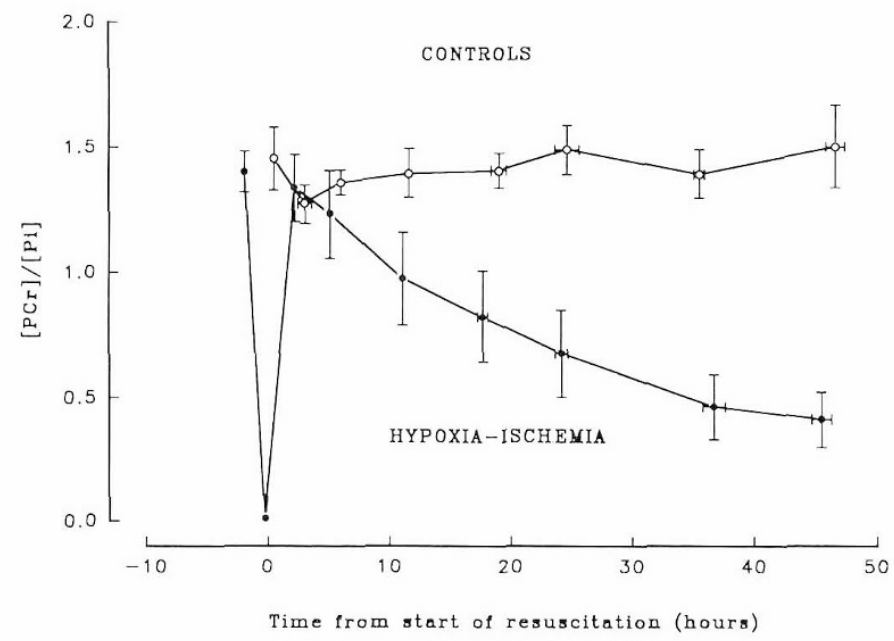

Figure 3. $[\mathrm{PCr}] /[\mathrm{Pi}]$ in the control group $(n=6)$ and the experimental group of piglets whose brains were subjected to acute hypoxia-ischemia $(n=12)$. Values are means and SEM.
The control spectrum illustrated in Figure 1 shows the expected prominent peaks due to $\mathrm{PCr}$ (peak 6) and NTP (peaks 7, 8, and 11). The $\beta$-NTP peak (peak 11) is mainly due to ATP. Other peaks are due to mobile components of cells, including PEt (peak 1) and phosphodiester (peaks 4 and 5). Two peaks (labeled $3 a$ and b) were found to resonate around the Pi frequency at about $5 \mathrm{ppm}$. The left-hand peak is thought to be due to extracellular and possibly mitochondrial $\mathrm{Pi}$, and the right-hand one to cytosolic Pi (19-21). An averaging method was used to derive the reported $\mathrm{pH}_{\mathrm{i}}$. The data given in Table 3 show that the ${ }^{31} \mathrm{P}$ metabolite concentration ratios in the control piglets remained close to baseline values for the $48 \mathrm{~h}$ during which observations continued.

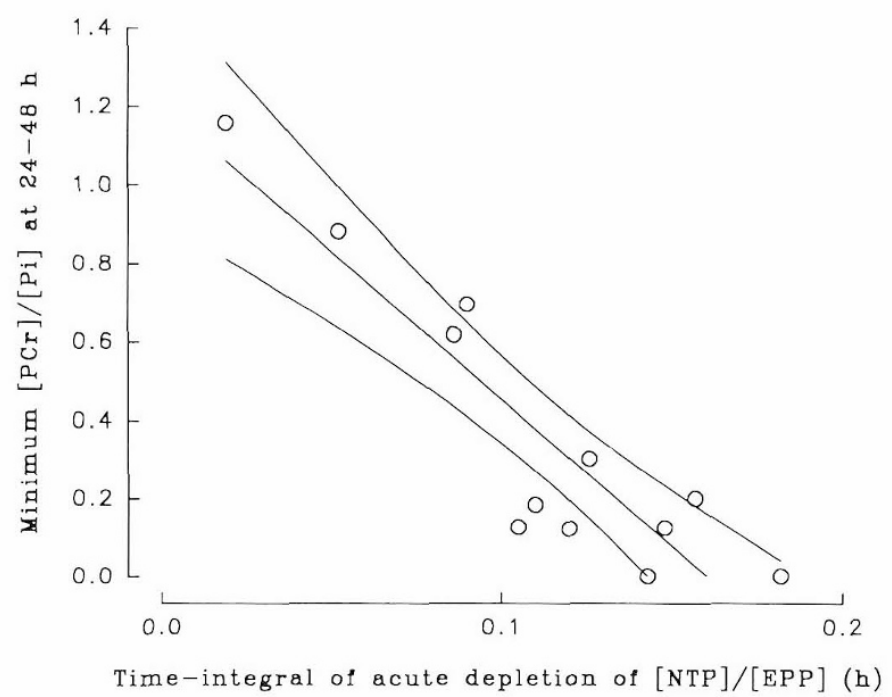

Figure 4. Relation between the extent of acute cerebral energy depletion, indicated by the time integral of depletion of [NTP]/[EPP], and the severity of subsequent secondary energy failure as shown by the minimum recorded values for $[\mathrm{PCr}] /[\mathrm{Pi}]$ at $24-48 \mathrm{~h}$. The regression line $(r=$ $0.91, p<0.0001)$ and its $95 \%$ confidence limits are shown. 
The cerebral circulation of the piglet is supplied by an intact circle of Willis (22) and includes vertebral as well as carotid components, so occluding the common carotid arteries leads to variably but substantially reduced cerebral blood flow. The reduction in $\mathrm{FiO}_{2}$ that caused $\mathrm{PaO}_{2}$ to decrease to $3.1 \pm 0.6 \mathrm{kPa}$ (Table 2 ) then critically curtailed the oxygen supply to the brain. This situation is likely to have been similar to that during severe birth asphyxia in human infants.

The changes in ${ }^{31} \mathrm{P}$ metabolites and $\mathrm{pH}_{\mathrm{i}}$ during the acute cerebral insult (Fig. 2, Table 4) resembled those reported in previous studies, including those of newborn animals $(8,9,23-25)$. The profound decrease in $\mathrm{pH}_{\mathrm{i}}$ was attributable in part to production of lactic acid. The objective of the acute insult, to reduce [NTP] as well as $[\mathrm{PCr}] /[\mathrm{Pi}]$, was achieved, thus indicating severe cerebral energy depletion. On reoxygenating and reperfusing the brain, recovery of ${ }^{31} \mathrm{P}$ metabolites and $\mathrm{pH}_{\mathrm{i}}$ was rapid, starting within $15 \mathrm{~min}$ and on average returning to baseline by $2 \mathrm{~h}$. This recovery was more complete than that in newborn rats subjected to permanent unilateral carotid occlusion and hypoxemia (25), which provide a more severe ongoing cerebral insult than that in the present experiments. Subsequently and in spite of normal values for arterial blood gases, blood glucose, and MABP, $[\mathrm{PCr}] /[\mathrm{Pi}]$ gradually declined, followed by $[\mathrm{NTP}] /[\mathrm{EPP}]$, in all but one experimental animal. These changes appeared identical with those previously described as secondary energy failure in birth-asphyxiated human infants $(2,5,6)$. Also as in the infants, $\mathrm{pH}_{\mathrm{i}}$ did not decrease, and in some animals progressive deterioration in cerebral energetics was seen, whereas in others apparent recovery was beginning by $48 \mathrm{~h}$. Prominent among mechanisms that may be implicated in the progression from primary to secondary energy failure are those involving excitotoxins such as glutamate, which initiates cellular damage mediated by nitric oxide and calcium; damage due to free radicals; immunocytotoxic reactions; impairment of protein synthesis; and lack of essential growth factors (24, 26-28). Ongoing ischemia is an unlikely explanation because cerebral blood flow appears increased in newborn infants with secondary energy failure (29), although some local microvascular failure may contribute. $\mathrm{pH}_{\mathrm{i}}$ is expected to decrease when mitochondrial energetics are compromised, e.g. by lack of oxygen during the primary insult, which decreases the metabolism of pyruvate by the mitochondrial respiratory chain. There are several possible explanations for the absence of a similar decrease during secondary energy failure. The time course was very slow. Lactic acid produced by damaged cells may have been washed out of the brain. Also, it is likely that damage was very heterogeneous. Mitochondrial function may have been preserved in some cells, whereas in others local ischemia could have caused lack of substrate (and thus no decrease in $\mathrm{pH}_{\mathrm{i}}$ ). Furthermore, dead cells would not produce lactate, and membrane failure would lead to the equalization of $\mathrm{pH}_{\mathrm{i}}$ and extracellular $\mathrm{pH}$.
During the acute cerebral hypoxic-ischemic insult, reduction of $[\mathrm{NTP}]$, quantified as $[\mathrm{NTP}] /[\mathrm{EPP}]$, was taken as the best index of energy depletion. These values were related to the subsequent decrease in $[\mathrm{PCr}] /[\mathrm{Pi}]$, which has been found to be the most sensitive index of secondary energy failure in human infants and to be directly related to prognosis $(2,5)$. Figure 4 shows that the greater the depletion of $[\mathrm{NTP}] /[\mathrm{EPP}]$ during the acute insult, the lower the $[\mathrm{PCr}] /[\mathrm{Pi}] 24-48 \mathrm{~h}$ later. A similar relation was demonstrated between [NTP]/[Ptot] [which has previously been used as an index of energy depletion $(1,2)]$ and later minimum $[\mathrm{PCr}] /[\mathrm{Pi}]$. Thus, the worse the episode of acute energy depletion, the greater the extent of the subsequent secondary energy failure. These data strongly suggest that the reason for the variation in the severity of secondary energy failure observed in human infants has a similar basis; specifically, the ones who display the most severe changes have been subjected to the most severe cerebral energy depletion before or around the time of birth.

The results of neuropathologic examination of the brain indicated necrosis, apoptosis, and secondary damage associated with cerebral edema. These changes were closely similar in nature and regional distribution to those seen in birth-asphyxiated infants; they will be described in detail elsewhere. Because the severity of secondary energy failure in the human infant is directly related to the chances of death or disability $(2,5)$, it is important that means are found to prevent it. The best way would be to prevent, by appropriate obstetric surveillance and intervention, the episode of primary energy failure that sets in train the biochemical reactions that lead later to the secondary phase. If this cannot be achieved, then it is possible that means may be found to interrupt the reactions. Methods for blocking them are becoming available, and evidence is also accumulating that hypothermia may have a useful role $(27,28,30)$.

Most studies of cerebroprotection have involved very small animals, such as the newborn rat, which are particularly useful for screening for suitable pharmacologic agents $(23,28)$. Before cerebroprotective strategies are applied to human infants who have suffered a severe acute hypoxic-ischemic insult to the brain, it will be important to prove their worth in a suitable animal model that is large enough for a wide range of systemic as well as cerebral observations to be made. The newborn piglet provides such a model, and we suggest that the prevention of secondary energy failure represented by minimum $[\mathrm{PCr}] /[\mathrm{Pi}]$ within $48 \mathrm{~h}$ could be used as an initial end point.

We conclude that, in the newborn piglet, 1) a severe acute episode of cerebral hypoxia-ischemia that is then reversed leads, after a delay of many hours, to the phenomenon that has previously been described as secondary energy failure in the birth-asphyxiated human infant, and 2) the severity of secondary energy failure is directly related to that of the primary insult. This animal model may be suitable for exploring further the mechanisms 
involved in the progression from primary to secondary energy failure and for testing strategies for preventing this progression.

Acknowledgments. The authors thank Dr. Marianne Thoresen for much helpful advice and Drs. M. V. Squier and S. J. Gould for the histopathologic reports.

\section{REFERENCES}

1. Hope PL, Costello AMdL, Cady EB, Delpy DT, Tofts PS, Chu A, Hamilton PA, Reynolds EOR, Wilkie DR 1984 Cerebral energy metabolism studied with phosphorus NMR spectroscopy in normal and birth-asphyxiated infants. Lancet 2:366-370

2. Azzopardi D, Wyatt JS, Cady EB, Delpy DT, Baudin J, Stewart AL, Hope PL, Hamilton PA, Reynolds EOR 1989 Prognosis of newborn infants with hypoxic-ischemic brain injury assessed by phosphorus magnetic resonance spectroscopy. Pediatr Res 25:445-451

3. Lolley RN 1961 The high energy phosphates in developing brain. J Neurochem 7:289-297

4. Mandel P, Edel-Hartt S 1966 Free nucleotides in the rat brain during postnatal development. J Neurochem 13:591-595

5. Roth SC, Edwards AD, Cady EB, Delpy DT, Wyatt JS, Azzopardi D, Baudin J, Townsend J, Stewart AL, Reynolds EOR 1992 Relation between cerebral oxidative metabolism following birth asphyxia and neurodevelopmental outcome and brain growth at one year. Dev Med Child Neurol 34:285-295

6. Reynolds EOR, Wyatt JS, Azzopardi D, Delpy DT, Cady EB, Cope M, Wray S, 1988 New non-invasive methods for assessing brain oxygenation and haemodynamics. Br Med Bull 44:1052-1075

7. Delpy DT, Gordon RE, Hope PL, Parker D, Reynolds EOR, Shaw D, Whitehead MD 1982 Noninvasive detection of cerebral ischemia by phosphorus nuclear magnetic resonance. Pediatrics 70:310-313

8. Hope PL, Cady EB, Delpy DT, Gardiner RM, Reynolds EOR 1987 Brain metabolism and intracellular $\mathrm{pH}$ during ischemia and hypoxia: an in vivo ${ }^{31} \mathrm{P}$ and ${ }^{1} \mathrm{H}$ nuclear magnetic resonance study in the lamb. J Neurochem 49:75-82

9. Laptook AR, Corbett JT, Nguyen HT, Peterson J, Nunnally RL 1988 Alterations in cerebral blood flow and phosphorylated metabolites in piglets during and after partial ischemia. Pediatr Res 23:206-211

10. Hannon JP, Bossone CA, Nade CE 1990 Normal physiological values for conscious pigs used in biomedical research. Lab Anim Sci 40:293-298

11. Morris GA, Freeman R 1978 Selective excitation in Fourier transform nuclear magnetic resonance. J Magn Reson Imaging 29:433-462

12. Cady EB 1991 A reappraisal of the absolute concentrations of phosphorylated metabolites in the human neonatal cerebral cortex obtained by fitting Lorent zian curves to the ${ }^{31} \mathrm{P}$ NMR spectrum. J Magn Reson Imaging 91:647-643

13. Petroff OAC, Prichard JW 1985 Cerebral intracellular $\mathrm{pH}$ by ${ }^{31} \mathrm{P}$ nuclear magnetic resonance spectroscopy. Neurology 35:781-788
14. Pettegrew JW, Withers E, Panchalingham K, Post JFM 1988 Considerations for brain $\mathrm{pH}$ assessment by ${ }^{31} \mathrm{P}$ NMR. Magn Reson Imaging 6:135-142

15. Glonek T, Kopp SJ, Kot E, Pettegrew JW, Harrison WH, Cohen MM 1982 P-31 nuclear magnetic resonance analysis of brain: the perchloric acid spectrum. J Neurochem 39:1210-1219

16. Raju RNK 1992 Some animal models for the study of perinatal asphyxia. Biol Neonate 62:202-214

17. Manohar M 1985 Impact of $70 \%$ nitrous oxide administration on regional distribution of brain blood flow in unmedicated healthy swine. J Cardiovasc Pharmacol 7:463-468

18. Stulken EH, Milde JH, Michenfelder JD, Tinker JH 1977 The nonlinear responses of cerebral metabolism to low concentrations of halothane, enflurane, isoflurane and thiopental. Anesthesiology 46:28-34

19. Portman MA, Ning XH 1990 Developmental adaptations in cytosolic phosphate content and $\mathrm{pH}$ regulation in the sheep heart in vivo. J Clin Invest 86:1823-1828

20. Robbins RC, Balaban RS, Swain JA 1990 Intermittent hypothermic asanguineous cerebral perfusion (cardioplegia) protects the brain during prolonged circulatory arrest. Thorac Cardiovasc Surg 99:878-884

21. Garlick PB, Sobell S, Bullock ER 1992 Evidence that mitochondrial phosphate is visible in ${ }^{31} \mathrm{P}$ NMR spectra of isolated perfused rat hearts. NMR Biomed 5:29-36

22. Becker H 1960 Arterien und venen am kopf des schweines. M.D. thesis, Tierarztlichen Hochschule, Hannover, Germany

23. Williams GD, Palmer C, Roberts RL, Heitjan DF, Smith MB $1992{ }^{31} \mathrm{P}$ NMR spectroscopy of perinatal hypoxic-ischemic brain damage: a model to evaluate neuroprotective drugs in immature rats. NMR Biomed 5:145-153

24. Palmer C, Brucklacher RM, Christensen MA, Vannucci RC 1990 Carbohy drate and energy metabolism during the evolution of hypoxic-ischemic brain damage in the immature rat. J Cereb Blood Flow Metab 10:227-235

25. Yager JY, Brucklacher RM, Vannucci RC 1992 Cerebral energy metabolism during hypoxia-ischemia and early recovery in immature rats. Am J Physio 262:H672-H677

26. Siesjo BK 1993 A new perspective on ischaemic brain damage. Prog Brain Res 96:1-9

27. Tan WKN, Williams CE, Gunn AJ, Mallard C, Gluckman PD 1993 Pretreatment with monosialoganglioside GM1 protects the brain of fetal sheep against hypoxic-ischemic injury without causing systemic compromise. Pediatr Res hypoxic-1sct
$34: 18-22$

28. Thordstein M, Bagenholm R, Thiringer K, Kjellmer I 1993 Scavengers of free oxygen radicals in combination with magnesium ameliorate perinatal hypoxicischemic damage in the rat. Pediatr Res 34:23-26

29. McCormick DC, Edwards AD, Roth SC, Wyatt JS, Elwell CE, Cope M Delpy DT, Reynolds EOR 1991 Relation between cerebral hemodynamics and outcome in birth asphyxiated newborn infants studied by near infrared spectroscopy. Pediatr Res 30:637

30. Ginsberg MD, Sternan LL, Globus M Y-T, Dietrich WD, Busto R 1992 Therapeutic modulation of brain temperature: relevance to ischemic brain injury. Cerebrovasc Brain Metab Rev 4:189-225 